\title{
Matrix metalloproteinases and tissue inhibitors of matrix metalloproteinases mRNA transcripts in the bronchial secretions of asthmatics
}

\author{
Didier D Cataldo ${ }^{1,2}$, Maud Gueders ${ }^{1}$, Carine Munaut ${ }^{2}$, Natacha Rocks ${ }^{1,2}$, Pierre Bartsch ${ }^{1}$, \\ Jean-Michel Foidart ${ }^{2}$, Agnes Noël ${ }^{2}$ and Renaud Louis ${ }^{1}$ \\ ${ }^{1}$ Department of Pneumology and ${ }^{2}$ Department of Biology of Tumor and Development, University of Liege, \\ Belgium
}

\begin{abstract}
Asthma is a chronic inflammatory disease characterized by profound extracellular matrix changes referred to as bronchial remodelling. In this study, we evaluated matrix metalloproteinases (MMPs) and tissue inhibitors of MMPs (TIMPs) mRNA expression in bronchial secretions of asthmatics and correlated MMPs modulations with the lung function as a reflection of the bronchial extracellular matrix remodelling. Quantitative RT-PCR was performed on cell pellets obtained from induced sputum in order to detect the mRNAs for MMP-1, $-2,-3,-8,-9$, $-12,-13$ TIMP-1, -2 , while semiquantitative RT-PCR was performed to assess the expression of MMP-7, monocyte chemoattractant protein-1 (MCP-1) and transforming growth factor- $\beta_{1}$ (TGF- $\beta_{1}$ ). The mRNA transcripts for MMP1, TIMP-1 and monocyte chemoattractant protein-1 (MCP-1) were increased in cell pellets of induced sputum from asthmatics when compared to controls $(P<0.05)$, and the intensity of MMP-1 mRNA expression inversely correlated with the FEV ${ }_{1}$ in asthmatics $(r=-0.49, P<0.05)$. The MMP-1 mRNA/TIMP-1 mRNA ratio correlated with the levels of MCP-1 mRNA in asthmatics $(r=0.47, P<0.05)$. There were no differences between the groups with respect to mRNA coding for MMP-2, $-3,-7,-8,-9,-12,-13,-14$, TIMP-2 and TGF- $\beta_{1}$. We conclude that cells contained in the bronchial secretions from asthmatics express higher amounts of mRNA for MMP-1 and TIMP-1, perhaps related to an increased expression of MCP-1, which might contribute to the extracellular matrix changes observed during airway remodelling.
\end{abstract}

Laboratory Investigation (2004) 84, 418-424, advance online publication, 16 February 2004; doi:10.1038/labinvest.3700063

Keywords: matrix metalloproteinases; tissue inhibitor of metalloproteinases; MCP-1; asthma; remodelling

Matrix metalloproteases (MMPs) compose an at least 26 member family of zinc-containing enzymes produced by many cell types and sharing structural and functional features. They are secreted from cells as inactive zymogens, bear a $\mathrm{Zn}$ atom at the active site, are made of five domains and are inhibited by the tissue inhibitors of MMPs (TIMPs). ${ }^{1}$ The MMPs are able to degrade the extracellular matrix components with a variable affinity depending on the subclasses. Recently, it has been shown that MMPs may participate in the fine tuning and repair process through regulation of the activity of chemokines/ cytokines and growth factors such as IL-8, IL-1 $\beta$ and

Correspondence: Dr D Cataldo MD, PhD, Department of Pneumology, University of Liege, CHU Sart-Tilman, Liege 4000, Belgium. E-mail: Didier.Cataldo@ulg.ac.be

Received 27 May 2003; revised 9 October 2003; accepted 15 October 2003; published online 16 February 2004 insulin-like growth factor-1 (IGF-1). ${ }^{2,3}$ TIMPs are a family of four members that inhibit the MMPs in a 1:1 relation. ${ }^{4}$

Asthma is an inflammatory disease of the airways, leading to progressive lung function impairment. ${ }^{5}$ In the last decade, interest has risen about the morphological changes that occur in the bronchial tree of such patients implicating profound extracellular matrix modifications and referred to as bronchial remodelling. ${ }^{6,7}$

Recently, it has been demonstrated that MMPs are likely to contribute to the pathogenesis of asthma. Indeed, many MMPs, including MMP-1, -2, -3, -8 and -9 , have been detected by various methods in the airways or the lung of such patients. ${ }^{8-10}$ In a mouse model of asthma, Kumagai et $a l^{11}$ have demonstrated that treating mice with broad-spectrum synthetic MMP inhibitors decreased the allergen-induced inflammation. In a similar model, we 
have demonstrated that MMP-9 KO mice did not develop airway hyperresponsiveness and displayed less peribronchial inflammation. ${ }^{12}$ Using a murine asthma model, Oh et $a l^{13}$ have recently reported that the plasminogen activator inhibitor-1 (PAI-1)-dependent inhibition of MMP-9 is a mechanism preventing the extracellular matrix deposition in the bronchial walls. It has been reported that MMP-9 and its inhibitor TIMP-1 were increased at the protein level in the lungs from asthmatics, ${ }^{8-10,14-16}$ and that bronchoalveolar lavage (BAL)-issued macrophages from asthmatics produce more MMP$9^{17}$ and TIMP- $1^{18}$ than controls. In addition, when compared to controls, asthmatics had in their bronchial secretions a lower MMP-9/TIMP-1 ratio measured by ELISA, which was found to be proportional to the disease severity. ${ }^{16}$ Nevertheless, other authors using immunohistochemistry described that MMP-9 was predominant over TIMP-1 in the bronchial walls of asthmatics. ${ }^{14}$ Regulation of MMPs expression and production is the result of a complex network of reciprocal interactions between different mediators and cells. Among these pathways, monocyte chemoattractant protein-1 (MCP-1) and transforming growth factor- $\beta_{1}$ (TGF- $\beta_{1}$ ), two mediators reported to be increased in the bronchial tree from asthmatics, ${ }^{19,20}$ have been demonstrated to induce the expression of MMP-1 in different cell types. ${ }^{21,22}$

We hypothesized that the upregulation of some MMPs and TIMPs genes expression in the sputum cells correlates with an increased bronchial remodelling and, therefore, with the lung function tests. The purpose of the present study was then to investigate the MMPs and TIMPs production at the mRNA level in the bronchial secretions, and to correlate this production with the sputum cellular content and the baseline lung function in asthmatics.

\section{Materials and methods}

\section{Subjects}

In all, 22 asthmatics and nine healthy controls participated in this study (Table 1). The patients were classified as suffering from mild asthma according to the American Thoracic Society (ATS) criteria (ATS guidelines for the diagnosis of asth$\mathrm{ma}^{23}$ ). None of the controls and asthmatics were current or previous smokers (Table 1). None of the subjects enroled in this study had suffered from a bronchial infection or from an asthma exacerbation for the 6 weeks preceding the study. All subjects gave their written informed consent and the protocol of the study was approved by the local ethical committee.

\section{Sputum Induction and Processing}

Sputum induction was performed as described previously ${ }^{8}$ by inhalation of hypertonic saline $(\mathrm{NaCl}$
Table 1 Patient characteristics

\begin{tabular}{lcc}
\hline & Controls & Asthma \\
\hline$N$ & 9 & 22 \\
Mean age & $31(23-40)$ & $35(18-65)$ \\
Sex ratio (M/F) & $4 / 5$ & $14 / 8$ \\
Tobacco & $9 \mathrm{NS}$ & $22 \mathrm{NS}$ \\
FEV1 (\% pred) & $92(82-114)$ & $89(36-123)$ \\
FEV1 (ml) & $3670(2430-4130)$ & $3366(1164-4920)$ \\
FEV1/VC & $81(72-97)$ & $76(39-94)$ \\
KCO (\%) & ND & $88(55-116)$ \\
PC 20 & & \\
Geometric mean) & $>16$ & 0.79 \\
Therapy & $9 \mathrm{NT}$ & $22 \mathrm{NT}$ \\
\hline
\end{tabular}

Values are expressed as mean (range).

$\mathrm{NT}=$ not treated (salbutamol as needed); NS $=$ nonsmoker, $\mathrm{ND}=$ not done; $\mathrm{KCO}=$ transfer coefficient for $\mathrm{CO} ; \mathrm{PC}_{20} \mathrm{M}=$ provocative dose of methacholine causing a $20 \%$ fall in $\mathrm{FEV}_{1}$

$4.5 \%$ ) after premedication by $400 \mu \mathrm{g}$ inhaled salbutamol. Aerosols were generated by an ultrasonic nebulizer (Devilbiss neb 2000) for $20 \mathrm{~min}$, the output of which was set at $1.5 \mathrm{ml} / \mathrm{min}$. Samples were collected in a sterile and RNAse-free Petri dish, immediately placed at $4^{\circ} \mathrm{C}$ and processed in maximum 15 min. The samples were diluted twice with dithiothreitol $5 \mathrm{mM}$ (DTT, Calbiochem) diluted in phosphate-buffered saline (PBS). The samples were then centrifuged at $400 \mathrm{~g}$ for $10 \mathrm{~min}$ at $4{ }^{\circ} \mathrm{C}$ in order to separate the cellular and the fluid phase. Cell pellets were mixed with a solution of guanidine thiocyanate $(5 \mathrm{M})$, snap frozen in liquid nitrogen and stored at $-80^{\circ} \mathrm{C}$ until the mRNA extraction (see below). Cell counts were performed on cytospins stained with Diff Quick ${ }^{\circ}$ (Dade) using morphological criteria and the supernatants were stored at $-80^{\circ} \mathrm{C}$. In all cases, 400 nonsquamous nucleated cells were counted by an experimented observer blinded to clinical details.

\section{RT-PCR for MMPs, TIMPs, MCP-1 and TGF- $\beta_{1}$ Transcripts}

Total RNA was obtained from the sputum cell pellets by using the cesium chloride ultracentrifugation $\operatorname{method}^{24}$ allowing the removal of mucous DNA. RNA levels and purity were assessed using a smartspect 3000 spectrophotometer (BioRad, Hercules, CA, USA). In order to rule out the possibility of genomic DNA contamination, all our RNA samples underwent a PCR with primers amplifying the 28S DNA. 28S ribosomal RNA (rRNA) and MMPs, TIMPs, MCP-1 and TGF- $\beta_{1}$ mRNAs were measured in $10 \mathrm{ng}$ aliquots of total RNA by RT-PCR. A known copy number of external control RNA template (synthetic RNA) was introduced in each sample to monitor the RT-PCR reaction and to allow the quantitation of each endogenous mRNA. ${ }^{25}$ RTPCR was performed using the GeneAmp Thermostable rTth reverse transcriptase RNA PCR kit 
Table 2 Characteristics of RT-PCR reaction

\begin{tabular}{|c|c|c|c|c|c|}
\hline & \multirow[b]{2}{*}{ Oligonucleotide sense } & \multirow[b]{2}{*}{ Oligonucleotide antisense } & \multicolumn{3}{|c|}{ Expected RNA size (bp) } \\
\hline & & & $\begin{array}{l}\text { Number } \\
\text { of PCR } \\
\text { cycles }\end{array}$ & Control & Endogenous \\
\hline MMP-1 & 5'-GAGCAAACACATCTGAGGTACAGGA-3' & 5'-TTGTCCCGATGATCTCCCCTGACA-3' & 36 & 267 & 185 \\
\hline MMP-2 & 5'-AGATCTTCTTCTTCAAGGACCGGTT-3' & $5^{\prime}$-GGCTGGTCAGTGGCTTGGGGTA-3' & 36 & 271 & 225 \\
\hline MMP-3 & 5'-GATCTCTTCATTTTGGCCATCTCTTC-3' & 5'-CTCCAGTATTTGTCСTCTACAAAGAA-3' & 35 & 272 & 246 \\
\hline MMP-7 & 5'-CCCCCCTGCATTTCAGGAA-3' & 5'-TCCTGGCCCATCAAATGG-3' & 30 & - & 100 \\
\hline MMP-8 & 5'-CCAAGTGGGAACGCACTAACTTGA- $3^{\prime}$ & 5'-TGGAGAATTGTCACCGTGATCTCTT-3' & 36 & 267 & 200 \\
\hline MMP-9 & $5^{\prime}$-GCGGAGATTGGGAACCAGCTGTA-3' & $5^{\prime}$-GACGCGCCTGTGTACACCCACA-3' & 35 & 266 & 208 \\
\hline MMP-12 & 5'-ACATTTCGCCTCTCTGCTGATGAC-3' & 5'-CAGAAACCTTCAGCCAGAAGAACC-3' & 36 & 262 & 201 \\
\hline MMP-13 & $\begin{array}{l}5^{\prime} \text {-ATGATCTTTAAAGACAGATTCTTCTGC- } \\
3^{\prime}\end{array}$ & 5'- TGGATAACCTTCCAGAATGTCATAA-3' & 38 & 270 & 203 \\
\hline MMP-14 & 5'- GGATACCCAATGCCCATTGGCCA-3' & 5'-CCATTGGGCATCCAGAAGAGAGC-3' & 32 & 269 & 221 \\
\hline TIMP-1 & $5^{\prime}$-CATCCTGTTGTTGCTGTGGCTGAT-3' & $5^{\prime}$-GTCATCTTGATCTCATAACGCTGG-3' & 35 & 295 & 176 \\
\hline TIMP-2 & 5'-CTCGCTGGACGTTGGAGGAAAGAA-3' & 5'-AGCCCATCTGGTACCTGTGGTTCA-3' & 29 & 269 & 155 \\
\hline MCP-1 & 5'-TAGCAGCCACCTTCATTCCCCAAG-3' & 5'-GTCTGGGGAAGGCTAGGGGAAAAT- ${ }^{\prime}$ & 38 & - & 182 \\
\hline TGF- $\beta_{1}$ & 5'-ACTACTACGCCAAGGAGGTCAC-3' & 5'-ACGTGCTGCTCCACTTTTAACT-3' & 38 & - & 202 \\
\hline $28 \mathrm{~S}$ & 5'-GTTCACCCACTAATAGGGAACGTGA-3' & 5'-GATTCTGACTTAGAGGCGTTCAGT-3' & 19 & 269 & 212 \\
\hline
\end{tabular}

(Perkin-Elmer, Branchburg, NJ, USA) and two pairs of primers (Gibco BRL-Life Technologies) (Table 2).

Reverse transcription was performed at $70^{\circ} \mathrm{C}$ for $15 \mathrm{~min}$ followed by $2 \mathrm{~min}$ incubation at $95^{\circ} \mathrm{C}$ for denaturation of RNA-DNA heteroduplexes. Amplification started at $94^{\circ} \mathrm{C}$ for $15 \mathrm{~s}, 68^{\circ} \mathrm{C}$ for $20 \mathrm{~s}$ and $72^{\circ} \mathrm{C}$ for $10 \mathrm{~s}$ and terminated by $2 \mathrm{~min}$ at $72^{\circ} \mathrm{C}$. RTPCR products were resolved on $10 \%$ acrylamide gels and analysed using a Fluor-S MultImager (Bio-Rad, Hercules, CA, USA) after staining with Gelstar dye (FMC Bioproducts, Rockland, ME, USA). Quantitative RT-PCR results are expressed as a ratio between the intensities of the bands corresponding to the endogenous RNA and to a synthetic RNA added in the RT-PCR reaction in known amounts. ${ }^{25}$ This ratio calculated for an MMP is further divided by the same ratio calculated for $28 \mathrm{~S}$ rRNA in the same sample. The results showed are mean of duplicates. MCP- 1 and TGF- $\beta 1$ RT-PCR were quantified by reporting the intensity of the band measured on a polyacrylamide gel to that of a $28 \mathrm{~S}$ rRNA in the corresponding sample (semiquantitative assessment).

\section{Statistical Analysis}

Comparisons between the groups were performed by a Mann-Whitney test. The correlations were sought by calculating the Spearman's coefficient of correlation. $P$-values $<5 \%$ were considered as statistically significant.

\section{Results}

\section{Demographic Characteristics of Patients}

The mean ages of patients with asthma and controls were similar. The asthmatics were classified as
Table 3 Total and differential sputum cell counts

\begin{tabular}{lcc}
\hline & Controls & Asthma \\
\hline Sputum weight (gr) & $2.67(0.75-6.7)$ & $4.35(1.43-8.92)$ \\
Viability (\%) & $92(71-100)$ & $92(77-100)$ \\
Squamous cells (\%) & $5(1-13)$ & $10(0-33)$ \\
Total nonsquamous & $1310(150-2180)$ & $1150(260-25390)$ \\
cells $\left(10^{3} / \mathrm{g}\right)$ & & \\
Macrophages (\%) & $59.8(25-71)$ & $41.6(4-83)$ \\
Macrophages $\left(10^{3} / \mathrm{g}\right)$ & $764(334-1245)$ & $550(85-5388)$ \\
Eosinophils $(\%)$ & $0.1(0-7.2)$ & $5.2^{* *}(0-67)$ \\
Eosinophils $\left(10^{3} / \mathrm{g}\right)$ & $2(0-94)$ & $59^{* *}(0-3555)$ \\
Neutrophils $(\%)$ & $19.5(7.2-55)$ & $23.2(1.4-80.6)$ \\
Neutrophils $\left(10^{3} / \mathrm{g}\right)$ & $213(81-1150)$ & $343(7-20464)$ \\
Lymphocytes $(\%)$ & $4.4(2.4-13)$ & $1.8^{* *}(0-5.2)$ \\
Lymphocytes $\left(10^{3} / \mathrm{g}\right)$ & $62(28-170)$ & $16^{*}(0-196)$ \\
Epithelial cells $(\%)$ & $6.8(1.8-33.2)$ & $8(1.4-48.4)$ \\
Epithelial cells $\left(10^{3} / \mathrm{g}\right)$ & $109(32-375)$ & $145(25-465)$ \\
\end{tabular}

The results are expressed as median (range) for both percentages and absolute values

${ }^{*} P<0.05$ vs controls.

${ }^{* *} P<0.005$ vs controls.

having mild asthma according to the guidelines of the ATS (ATS guidelines for the diagnosis of asthma, ${ }^{23}$ ). Most of the asthmatics had a normal basal lung function and the mean $\mathrm{FEV}_{1}$ was not significantly different from that of controls. None of the asthmatics had been treated by inhaled or oral steroids within the last 6 weeks or reported a smoking history (Table 1).

\section{Total and Differential Cell Counts in Induced Sputum}

Sputum cell counts are shown as both absolute cell counts (cell number/g of sputum) and percentages of total cell counts (Table 3). As expected, eosinophil counts were higher in asthmatics when considering 
both the percentage or absolute cell counts $(P<0.005)$.

MMPs, TIMPs, MCP-1 and TGF- $\beta_{1}$ mRNA Expression by Sputum Cells

The mRNA transcripts for MMP-1, TIMP-1 and MCP-1 were significantly increased in the sputum cell pellets from asthmatics $(P<0.05)$ (Figures $1 \mathrm{a}-\mathrm{C}$ and 2). MCP-1 mRNA levels were significantly correlated with MMP-1 mRNA/TIMP-1 mRNA ratio in asthmatics $(r=0.47, P<0.05)$ (Figure 3). MMP-9 and -12 mRNA levels were not significantly modified in asthmatics when compared to controls
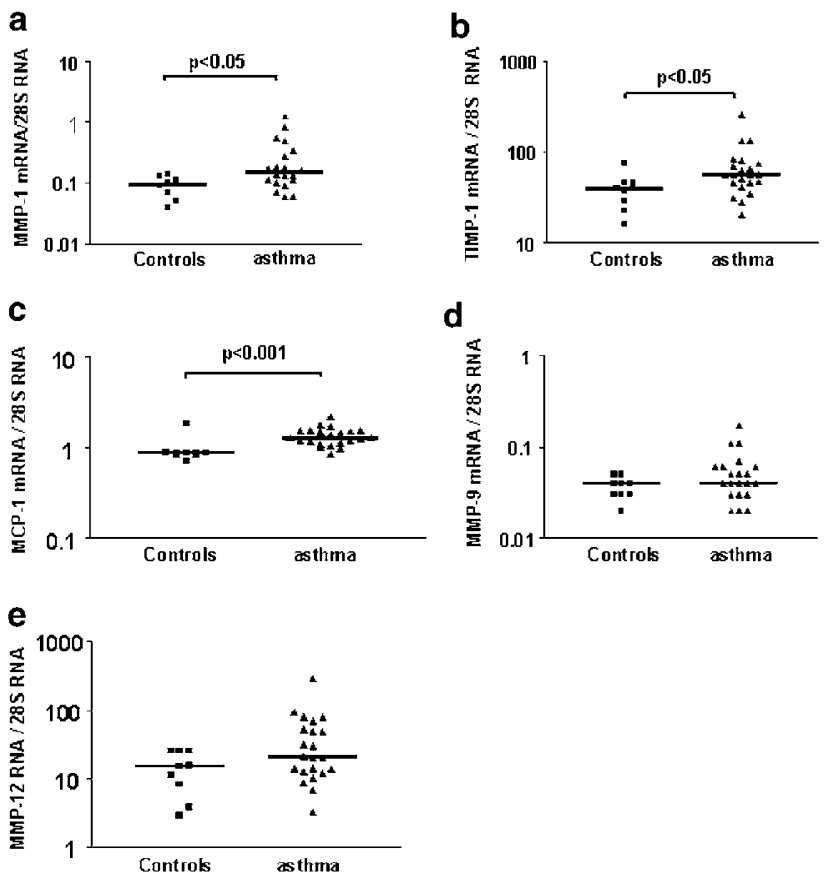

Figure 1 mRNA levels in the extracts from cell pellets measured in quantitative RT-PCR. The results are expressed in arbitrary units, corresponding to a ratio between the number of mRNA copies and 28S rRNA for each sample. The horizontal bars represent the median values.
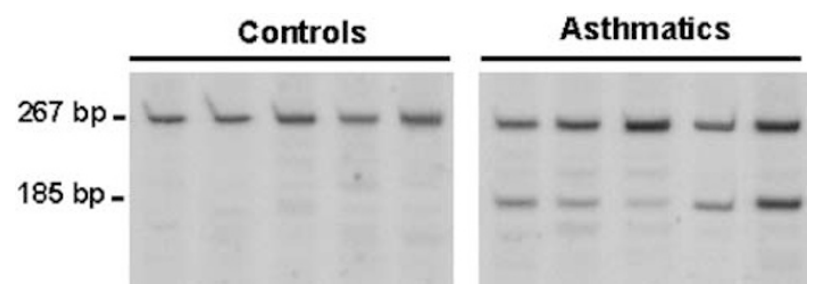

Figure 2 Representative examples of RT-PCR for MMP-1 mRNA performed on $10 \mathrm{ng}$ aliquots of RNA extracted from sputum cells from five control subjects and five asthmatics. The upper band (267 bp) corresponds to the internal standard, made of a synthetic RNA (see Materials and methods) and added in known amounts in the RT-PCR reaction, while the lower band (185 bp) represents the endogenous RNA amplification. $10 \%$ polyacrylamide gels are stained with Gelstar ${ }^{\circledR}$.

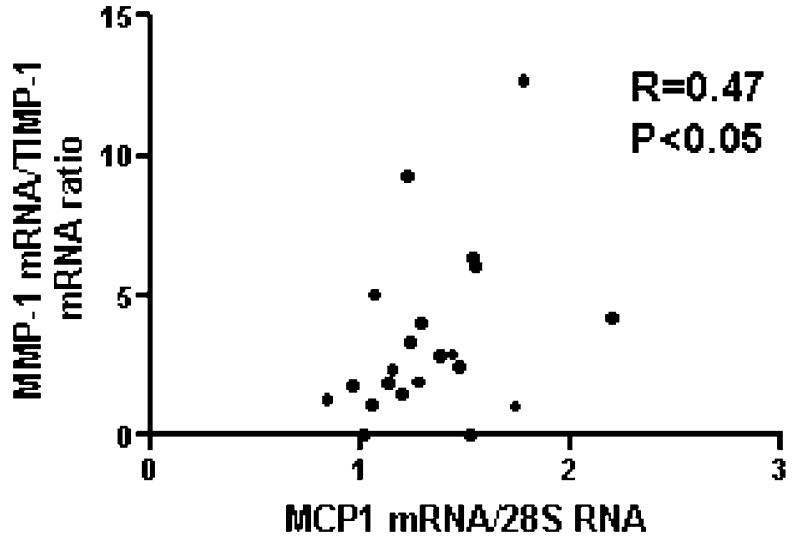

Figure 3 Relationship between the MMP-1mRNA/TIMP-1 mRNA ratio and the expression levels of MCP-1 mRNA in the sputum cell from asthmatics.

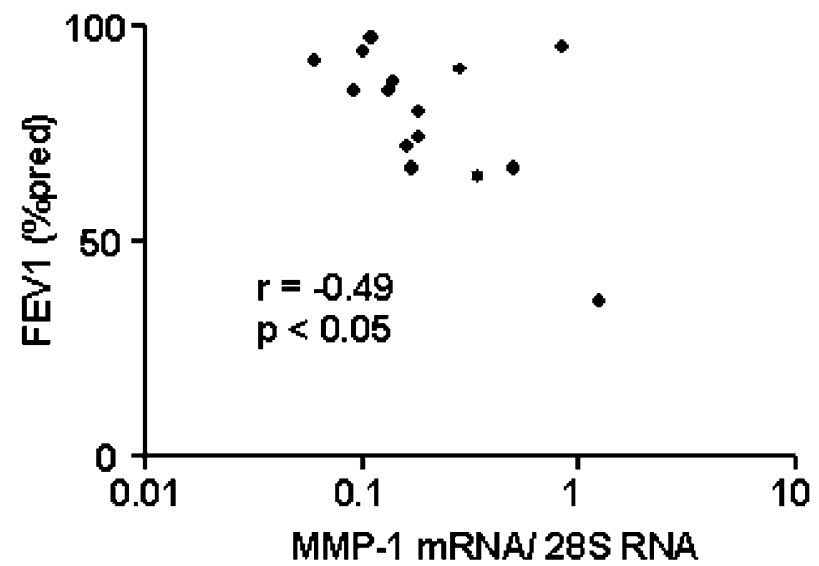

Figure 4 Relationship between the levels of MMP-1 mRNA expression and baseline $\mathrm{FEV}_{1}$ expressed as \% predicted in sputum cells from asthmatics.

(Figure $1 \mathrm{~d}, \mathrm{e}$ ). MMP-2, -7, -14, TIMP-2 and TGF- $\beta_{1}$ mRNA levels were detectable in each sample without any significant difference between the groups (data not shown). MMP-8 mRNAs were barely detectable and have not been quantified, while those for MMP-3 and -13 were not detectable in our samples. The calculated ratio between the number of mRNA copies of MMP-9 and TIMP-1 was not different between the groups.

\section{Correlations between Sputum MMPs, TIMPs and FEV}

In asthmatics, MMP-1 mRNA levels were negatively correlated with baseline $\mathrm{FEV}_{1}(r=-0.49, P<0.05)$ (Figure 4).

\section{Discussion}

We describe here for the first time that mRNA transcripts for MMP-1 and TIMP-1 are increased in the sputum cells from asthmatics. Furthermore, we 
demonstrate that the amounts of MMP-1 mRNA transcripts are related to $\mathrm{FEV}_{1}$ impairment in asthmatics.

MMP-1 is mainly secreted by fibroblasts and activated monocytes/macrophages. ${ }^{26,27}$ MMP-1 was shown to be overexpressed in the lungs of patients with emphysema ${ }^{27}$ and COPD $^{28}$ but not in asthmatics, although MMP-1 protein was barely detectable in BAL fluid from latter. ${ }^{10}$ Although it displays a rather limited proteolytic spectrum when considering the extracellular matrix, MMP-1 is a major protease capable of degrading fibrillar collagen, and the increased levels of MMP-1 gene expression could be associated in asthmatics with the bronchial remodelling that mainly consists of cycles of degradation and impaired repair. ${ }^{6}$ In addition, MMP-1 is likely to play roles other than breaking down fibrillar collagen. In particular, it can also degrade insulin-like growth factor binding proteins (IGF-BP)-1 and -3, thereby increasing the bioavailability of IGF-1, a potent growth factor for airway smooth muscle. ${ }^{3}$ Our observation of increased expression of MMP-1 in asthma is in line with a recent report demonstrating an overexpression of MMP-1 mRNA by human monocytes when stimulated by Th2 polarized lymphocytes. ${ }^{29}$ Our study should be confirmed by immunohistochemistry or Western blot in order to assess the protein production of MMP-1. The reason why mRNA for MMP-1 was increased in asthma could be linked to the action of some proinflammatory cytokines encountered in asthma that are known to be able to upregulate the MMP-1 gene expression in different cells. For instance, it has been shown in an animal model of asthma that the specific inhibition of MCP1 diminishes drastically bronchial airway hyperresponsiveness and inflammation. ${ }^{30}$ In the present study, we describe an increased mRNA expression for MCP-1 in sputum cells from asthmatics and we found a correlation between MCP-1 expression and the ratio between MMP-1 and TIMP-1 mRNA, indicating that MCP-1 may account for an increased MMP-1 proteolytic activity, and thereby participate in the inflammation and remodelling processes of the airways that take place in asthma. However, the relationship between the two expression is not demonstrated by our data and one can speculate that MCP-1 could increase MMP-1 expression in the sputum cells simply by a chemotactic effect increasing the macrophage number in the airway lumen. However, in the present study there were no significant differences in macrophage counts between asthmatics and controls, indicating that such a chemotactic effect of MCP-1 is not the main cause of MMP-1 overexpression.

In our previous studies, ${ }^{8,31}$ both quantitative zymography and ELISA have shown that the MMP-9 protein was increased in the bronchial secretions from asthmatics. These raised levels of MMP-9 in sputum supernatants from asthmatics, which contrast with the lack of increased mRNA expression from sputum cells, point to an excessive release of the protein from intracytoplasmic stores. Knowing that neutrophils may synthesize high amounts of MMP-9 and store it in the secondary granules, ${ }^{24,32}$ the absence of MMP-9 mRNAs enhancement in the sputum cells from asthmatics could be ascribed to a neutrophil degranulation process occurring in the airways from those patients perhaps enhanced by a neutrophil activation. In addition, MMP-9 released from neutrophils may in turn amplify the neutrophils recruitment by processing the interleukin-8 (IL-8) by cleaving six amino acids, resulting in an IL-8 ${ }^{7-77}$ being 10 times more potent chemoattractant for neutrophils. ${ }^{2}$ However, it is worth to note that the cellular origin of MMP-9, which appears as one of the major proteases present in the airways of asthmatics, is likely to be plural. Indeed, other authors have described an overproduction of MMP-9 by other cell types such as epithelial cells, macrophages and eosinophils in asthma. ${ }^{15,17,33}$ An alternative explanation for dissociated MMP-9 levels in proteins and mRNAs would be that the proportion of migrating epithelial cells secreting high levels of MMP-9 in the bronchial lumen and secretions is increased in asthmatics. ${ }^{34}$ Nevertheless, it should be kept in mind that the detection of the expression of mRNAs corresponding to such proteins does not necessarily implicate that the protein is effectively secreted by cells.

In line with our previous findings of increased TIMP-1 protein levels in the sputum from asthmatics, ${ }^{8}$ TIMP-1 mRNA expression is increased in the sputum from asthmatics. Besides confirming the previous works indicating that TIMP-1 is increased in the bronchial secretions of asthmatics ${ }^{8,16,18}$ we are adding new data regarding TIMP-1 mRNA expression in the airways. TIMP-1 is a potent inhibitor of MMP-1 and -9 and is secreted by many cell types. Recently, it has been demonstrated that MMP-9 originating from neutrophils is in part complexed to its inhibitor, TIMP- $1,{ }^{35}$ and that TIMP-1 is produced by neutrophils, ${ }^{24}$ and stored in specific cytoplasmic vesicles. ${ }^{36}$ However, as discussed earlier for MMP-9, TIMP-1 might also originate from other cells and namely from macrophages. ${ }^{10}$

We did not find at the mRNA level the decreased MMP-9/TIMP-1 ratio previously reported at the protein level in asthma. ${ }^{16}$ This could be explained by the fact that our asthmatic patients were stable asthmatics and less severe in terms of function loss than those previously studied, and that we have studied mRNA levels that could not reflect the MMP-9 and TIMP-1 protein secretion from intracellular stores, for example. ${ }^{32,35}$ It is also worth noting that a study conducted on bronchial biopsies from asthmatics showed that MMP-9 immunoreactivity was higher than that of TIMP-1 in the epithelium and submucosa, which is probably another compartment, not explored by the study of sputum. ${ }^{14} \mathrm{We}$ acknowledge that the MMP/TIMP ratios are not equivalent when considered at protein or mRNA 
level and could not reflect the real state of activation of the proteins.

A rather unusual finding of this study is the fact that asthmatics display lower lymphocyte counts than healthy subjects in their sputum. Although unusual, this finding has previously been reported in other papers ${ }^{37}$ and many reports have described that the lymphocyte counts are poorly reproducible. ${ }^{38,39}$

In conclusion, our results indicate that induced sputum cells collected from asthmatics displayed an increased transcription for MMP-1 and TIMP-1. This excessive transcription of matrix metalloprotease may significantly contribute to airway remodelling in asthma and suggest applying an animal model of asthma to human MMP-1 expressing transgenic mice $^{40}$ in order to investigate the precise effects of MMP-1 overexpression on the bronchial wall extracellular matrix composition in the context of a repeated allergen exposure.

\section{Acknowledgement}

We thank Fabienne Perin, Jocelyne Sele and Laure Volders for technical assistance. This work was supported by grants from the Fonds National de la Recherche Scientifique (FNRS, Brussels, Belgium) (FRSM 3.4603.98), the Fondation Leon Fredericq (University of Liege), and the CHU, Liege, Belgium. DC is a postdoctoral researcher of the FNRS. CM and AN are research associate and senior research associate of the FNRS, respectively.

\section{References}

1 Shapiro SD. Matrix metalloproteinase degradation of extracellular matrix: biological consequences. Curr Opin Cell Biol 1998;10:602-608.

2 Opdenakker G, Van den Steen PE, Dubois B, et al. Gelatinase B functions as regulator and effector in leukocyte biology. J Leukoc Biol 2001;69:851-859.

3 Rajah R, Nachajon RV, Collins $\mathrm{MH}$, et al. Elevated levels of the IGF-binding protein protease MMP-1 in asthmatic airway smooth muscle. Am J Respir Cell Mol Biol 1999;20:199-208.

4 Gomez DE, Alonso DF, Yoshiji H, et al. Tissue inhibitors of metalloproteinases: structure, regulation and biological functions. Eur J Cell Biol 1997;74: 111-122.

5 Lange P, Parner J, Vestbo J, et al. A 15-year follow-up study of ventilatory function in adults with asthma. N Engl J Med 1998;339:1194-1200.

6 Bousquet J, Chanez P, Lacoste JY, et al. Asthma: a disease remodeling the airways. Allergy 1992;47: 3-11.

7 Jeffery PK. Comparative morphology of the airways in asthma and chronic obstructive pulmonary disease. Am J Respir Crit Care Med 1994;150:S6-S13.

8 Cataldo D, Munaut C, Noel A, et al. MMP-2- and MMP9-linked gelatinolytic activity in the sputum from patients with asthma and chronic obstructive pulmon- ary disease. Int Arch Allergy Immunol 2000;123: 259-267.

9 Dahlen B, Shute J, Howarth P. Immunohistochemical localisation of the matrix metalloproteinases MMP-3 and MMP-9 within the airways in asthma. Thorax 1999;54:590-596.

10 Mautino G, Henriquet C, Jaffuel D, et al. Tissue inhibitor of metalloproteinase-1 levels in bronchoalveolar lavage fluid from asthmatic subjects. Am J Respir Crit Care Med 1999;160:324-330.

11 Kumagai K, Ohno I, Okada S, et al. Inhibition of matrix metalloproteinases prevents allergen-induced airway inflammation in a murine model of asthma. J Immunol 1999;162:4212-4219.

12 Cataldo DD, Tournoy KG, Vermaelen K, et al. Matrix metalloproteinase-9 deficiency impairs cellular infiltration and bronchial hyperresponsiveness during allergen-induced airway inflammation. Am J Pathol 2002;161:491-498.

13 Oh CK, Ariue B, Alban RF, et al. PAI-1 promotes extracellular matrix deposition in the airways of a murine asthma model. Biochem Biophys Res Commun 2002;294:1155-1160.

14 Hoshino M, Nakamura Y, Sim J, et al. Bronchial subepithelial fibrosis and expression of matrix metalloproteinase-9 in asthmatic airway inflammation. J Allergy Clin Immunol 1998;102:783-788.

15 Ohno I, Ohtani H, Nitta Y, et al. Eosinophils as a source of matrix metalloproteinase- 9 in asthmatic airway inflammation. Am J Respir Cell Mol Biol 1997;16:212-219.

16 Vignola AM, Riccobono L, Mirabella A, et al. Sputum metalloproteinase-9/tissue inhibitor of metalloproteinase-1 ratio correlates with airflow obstruction in asthma and chronic bronchitis. Am J Respir Crit Care Med 1998;158:1945-1950.

17 Mautino G, Oliver N, Chanez P, et al. Increased release of matrix metalloproteinase-9 in bronchoalveolar lavage fluid and by alveolar macrophages of asthmatics. Am J Respir Cell Mol Biol 1997;17:583-591.

18 Mautino G, Henriquet C, Gougat C, et al. Increased expression of tissue inhibitor of metalloproteinase-1 and loss of correlation with matrix metalloproteinase-9 by macrophages in asthma. Lab Invest 1999;79: 39-47.

19 Sousa AR, Lane SJ, Nakhosteen JA, et al. Increased expression of the monocyte chemoattractant protein-1 in bronchial tissue from asthmatic subjects. Am J Res Cell Mol Biol 1994;10:142-147.

20 Vignola AM, Chanez P, Chiappara G, et al. Transforming growth factor-beta expression in mucosal biopsies in asthma and chronic bronchitis. Am J Respir Crit Care Med 1997;156:591-599.

21 Yamamoto T, Eckes B, Mauch C, et al. Monocyte chemoattractant protein-1 enhances gene expression and synthesis of matrix metalloproteinase-1 in human fibroblasts by an autocrine IL-1 alpha loop. J Immunol 2000;164:6174-6179.

22 Cheon H, Yu SJ, Yoo DH, et al. Increased expression of pro-inflammatory cytokines and metalloproteinase-1 by TGF-beta1 in synovial fibroblasts from rheumatoid arthritis and normal individuals. Clin Exp Immunol 2002;127:547-552.

23 Standards for the diagnosis and care of patients with chronic obstructive pulmonary disease (COPD) and asthma. This official statement of the American Thoracic Society was adopted by the ATS Board of 
Directors, November 1986. Am Rev Respir Dis 1987;136:225-244.

24 Cataldo D, Munaut C, Noel A, et al. Matrix metalloproteinases and TIMP-1 production by peripheral blood granulocytes from COPD patients and asthmatics. Allergy 2001;56:145-151.

25 Lambert CA, Colige AC, Munaut C, et al. Distinct pathways in the over-expression of matrix metalloproteinases in human fibroblasts by relaxation of mechanical tension. Matrix Biol 2001;20:397-408.

26 Emonard H, Calle A, Grimaud JA, et al. Interactions between fibroblasts and a reconstituted basement membrane matrix. J Invest Dermatol 1987;89:156-163.

27 Finlay GA, O’Driscoll LR, Russell KJ, et al. Matrix metalloproteinase expression and production by alveolar macrophages in emphysema. Am J Respir Crit Care Med 1997;156:240-247.

28 Segura-Valdez L, Pardo A, Gaxiola M, et al. Upregulation of gelatinases A and B, collagenases 1 and 2, and increased parenchymal cell death in COPD. Chest 2000;117:684-694.

29 Chizzolini C, Rezzonico R, De Luca C, et al. Th2 cell membrane factors in association with IL-4 enhance matrix metalloproteinase-1 (MMP-1) while decreasing MMP-9 production by granulocyte-macrophage colony-stimulating factor-differentiated human monocytes. J Immunol 2000;164:5952-5960.

30 Gonzalo JA, Lloyd CM, Wen D, et al. The coordinated action of CC chemokines in the lung orchestrates allergic inflammation and airway hyperresponsiveness. J Exp Med 1998;188:157-167.

31 Cataldo DD, Bettiol J, Noel A, et al. Matrix metalloproteinase-9, but not tissue inhibitor of matrix metalloproteinase-1, increases in the sputum from allergic asthmatic patients after allergen challenge. Chest 2002;122:1553-1559.

32 Kjeldsen L, Sengelov H, Lollike K, et al. Isolation and characterization of gelatinase granules from human neutrophils. Blood 1994;83:1640-1649.

33 Yao PM, Lemjabbar H, D’Ortho MP, et al. Balance between MMP-9 and TIMP-1 expressed by human bronchial epithelial cells: relevance to asthma. Ann N Y Acad Sci 1999;878:512-514.

34 Legrand C, Polette M, Tournier JM, et al. uPA/plasmin system-mediated MMP-9 activation is implicated in bronchial epithelial cell migration. Exp Cell Res 2001;264:326-336.

35 Triebel S, Blaser J, Gote T, et al. Evidence for the tissue inhibitor of metalloproteinases-1 (TIMP-1) in human polymorphonuclear leukocytes. Eur J Biochem 1995;231:714-719.

36 Price B, Dennison C, Tschesche H, et al. Neutrophil tissue inhibitor of matrix metalloproteinases-1 occurs in novel vesicles that do not fuse with the phagosome. J Biol Chem 2000;275:28308-28315.

37 Bettiol J, Sele J, Henket M, et al. Cytokine production from sputum cells after allergenic challenge in IgEmediated asthma. Allergy 2002;57:1145-1150.

38 Cataldo D, Foidart JM, Lau LC, et al. Induced sputum: comparison between isotonic and hypertonic saline in asthma. Chest 2001;120:1815-1821.

39 Spanevello A, Migliori GB, Sharara A, et al. Induced sputum to assess airway inflammation: a study of reproducibility. Clin Exp Allergy 1997;27: 1138-1144.

40 D'Armiento J, Dalal SS, Okada Y, et al. Collagenase expression in the lungs of transgenic mice causes pulmonary emphysema. Cell 1992;71:955-961. 